\title{
Tsafon
}

Revue d'études juives du Nord

$81 \mid 2021$

Des synagogues à travers les âges Lieux de prières, lieux d'études et autres fonctions

\section{Horvilleur Delphine, Vivre avec nos morts}

\section{Danielle Delmaire}

\section{(2) OpenEdition \\ 1 Journals}

\section{Édition électronique}

URL : https://journals.openedition.org/tsafon/4055

DOI : 10.4000/tsafon.4055

ISSN : 2609-6420

Éditeur

Association Jean-Marie Delmaire

\section{Édition imprimée}

Date de publication : 1 juillet 2021

Pagination : 167-168

ISSN : 1149-6630

\section{Référence électronique}

Danielle Delmaire, "Horvilleur Delphine, Vivre avec nos morts », Tsafon [En ligne], 81 | 2021, mis en ligne le 01 juillet 2021, consulté le 16 septembre 2021. URL : http://journals.openedition.org/tsafon/4055 ; DOI : https://doi.org/10.4000/tsafon.4055

Ce document a été généré automatiquement le 16 septembre 2021.

Tsafon. Revues d'études juives du Nord 


\title{
Horvilleur Delphine, Vivre avec nos
}

\section{morts}

\author{
Danielle Delmaire
}

\section{RÉFÉRENCE}

Horvilleur Delphine, Vivre avec nos morts, Paris, Grasset, 2021, 223 p., 19,50€.

D'emblée arrêtons-nous sur le titre pour remarquer l'antinomie entre "vivre » et «morts » et retenir le possessif «nos ». Tout au long de l'ouvrage, la vie et la mort sont associées et le lecteur referme le livre avec ces derniers mots en hébreu : «LeH'ayim ! », «À la vie!", souhait que l'on émet auprès de personnes dont on veut du bien. Il s'agit bien d'un livre sur la vie comme sur la mort car ce «LeH'ayim! » ponctue les chapitres. Il s'agit aussi de vivre avec les morts auxquels nous sommes attachés, nos proches, nos amis, bref des intimes.

2 Onze chapitres composent l'ouvrage dans lesquels la rabbine revient sur ses expériences d'accompagnement de familles lors de funérailles, au bord de la tombe mais aussi au domicile du défunt ou encore en tout autre lieu, là où elle a été convoquée. Ce récit de ses expériences est l'occasion, maintes fois, de renseigner sur les coutumes et les rites funéraires juifs, sur les croyances des juifs et sur leur histoire. En d'autres pages, ce sont des mots hébreux, mots clés du judaïsme, qui sont expliqués avec des précisions sur leur sémantique et leur usage. De la sorte, l'ouvrage ne s'adresse pas aux initiés juifs mais il est abordable par tout lecteur ignorant du judaïsme. Les références à des textes rabbiniques, du Talmud ou de la Mishna ou encore du Shoulhan aroukh, la Loi juive codifiée au XVI ${ }^{e}$ siècle par Joseph Karo, sont les bienvenues sans oublier les truculentes « histoires juives », salutaire détente.

Chacun des onze chapitres porte en titre le nom d'un défunt ou d'un proche du défunt. L'on peut répartir les témoignages en trois catégories : son soutien à des membres de la communauté que l'auteure encadre en tant que rabbine, sa présence auprès de 
personnalités qu'elle a côtoyées, son souvenir de personnages bibliques à propos d'un décès.

4 La première catégorie est la plus fournie. En diverses occasions, Delphine Horvilleur eut à aider des familles à réaliser un deuil. Tâche ardue et l'auteure partage avec le lecteur ses doutes, ses efforts et parfois ses maladresses dues à l'impuissance de consoler. «Trouver les mots et connaître ces gestes est le cœur de mon travail «(p. 16), reconnaît-elle. Il en va ainsi pour Azraël ( $1^{\mathrm{er}}$ chap.); Marc ( $3^{\mathrm{e}}$ chap) pour lequel elle ne souhaite pas dramatiser la mort, la séparation; Sarah ( $4^{\mathrm{e}}$ chap.), la cosette du ghetto dont la vie fut une longue et perpétuelle souffrance avoue son fils; le frère d'Isaac ( $6^{\mathrm{e}}$ chap.) qui exige de savoir où désormais se trouve son frère décédé : au ciel ou ailleurs, il doit savoir pour mieux vivre; Ariane ( $7^{e}$ chap.) l'amie ou jumelle tant Delphine Horvilleur lui ressemble tout en étant si différente ; et enfin Myriam ( $8^{\mathrm{e}}$ chap.) obsédée par ses funérailles auxquelles elle finit par assister de son vivant!

5 La seconde catégorie plus brève fait état de trois accompagnements : celui d'Elsa Cayat de Charlie Hebdo ( ${ }^{\mathrm{e}}$ chap.) dont elle partageait l'amitié malgré les différences d'implication dans le judaïsme ; celui de Marceline et Simone ( $5^{\mathrm{e}}$ chap.), inséparables, Delphine Horvilleur se trouve aux côtés de Marceline lors des obsèques de Simone et du transfert de ses cendres au Panthéon ce qui lui permet de restituer la gouaille de Marceline ; celui d'Isthaq Rabin ( $10^{\mathrm{e}}$ chap.) dont elle n'accompagne pas les funérailles mais elle relate les circonstances dans lesquelles elle vécut ce drame alors qu'ellemême vivait en Israël qu'elle a quitté par la suite.

6 La troisième catégorie est encore plus brève avec deux récits : celui de Moïse ( $9^{\mathrm{e}} \mathrm{chap}$.) «l'homme qui ne voulait pas mourir » qui donne l'occasion de relire le texte biblique et celui d'Edgard (11 ehap.), oncle de l'auteure dont le regard figé dans un tableau de famille scrute la petite fille qu'était l'auteure à la manière dont « l'œil » poursuit Caïn jusque dans la tombe, référence à Hugo.

7 Sollicitée toujours dans la précipitation puisque, dans le judaïsme, les funérailles suivent de très près le décès, la rabbine Delphine Horvilleur fait part de ses doutes, sans ostentation et souvent avec sincérité. Le lecteur partage très volontiers ses hésitations et peut la remercier de mieux faire connaître les rites funéraires juifs, le judaïsme en général et ses croyances en particulier. Un bel ouvrage à mettre entre les mains de quiconque souhaite connaître le métier de rabbin. 